
\title{
$\begin{array}{ll}\text { Research Square } & \text { Preprints are preliminary reports that have not undergone peer review. } \\ \text { They should not be considered conclusive, used to inform clinical practice, } & \text { or referenced by the media as validated information. }\end{array}$
}

\section{Comparison of vascular invasion with lymph node metastasis as a prognostic factor in stage I-III colon cancer: an observational cohort study}

\section{Jung Hoon Bae}

Seoul St. Mary's Hospital, The Catholic University of Korea

Chul Seung Lee

Seoul St. Mary's Hospital, The Catholic University of Korea

Seung-Rim Han

Seoul St. Mary's Hospital, The Catholic University of Korea

Ji Hoon Kim

Incheon St. Mary's Hospital, The Catholic University of Korea

\section{Bong-Hyeon Kye}

St. Vincent's Hospital, The Catholic University of Korea

In Kyu Lee

Seoul St. Mary's Hospital, The Catholic University of Korea

Yoon Suk Lee ( $\nabla$ yslee@catholic.ac.kr)

Catholic University of Korea School of Medicine https://orcid.org/0000-0002-1849-2774

\section{Research}

Keywords: Colonic neoplasm, Vascular invasion, Lymph node metastasis, Prognosis, Recurrence pattern

Posted Date: July 8th, 2020

DOl: https://doi.org/10.21203/rs.3.rs-40424/v1

License: (c) (1) This work is licensed under a Creative Commons Attribution 4.0 International License. Read Full License 


\section{Abstract}

Background: The oncological impact of vascular invasion (VI), when compared with that of lymph node metastasis (LNM), has been underestimated in clinicopathological staging of colon cancer. This study aimed to evaluate the prognostic impact of $\mathrm{VI}$ in comparison with that of LNM in non-metastatic colon cancer.

Methods: Patients who underwent surgery for stage I-III colon cancer were divided into four groups depending on the status of VI and LNM (Group I: VI-/LNM-; Group II: VI+/LNM-; Group III: VI-/LNM+; Group IV: VI+/LNM+). Group III was subdivided according to the node (N) stage (Group IIIA: VI-/N1; Group IIIB:

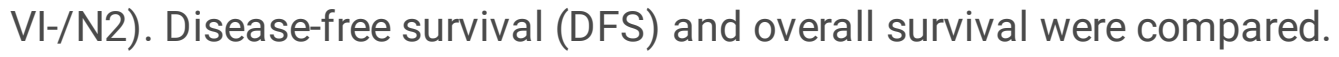

Results: In total, 793 non-metastatic colon cancer patients were included. Group II (hazard ratio [HR] 2.34, 1.01-5.41), Group III (HR 1.91, 1.26-2.89), and Group IV (HR 2.34, 1.33-4.14) were independently associated with poor DFS. All recurrences in Group II occurred within 2 years and were distant metastases. The 1- and 2-year DFS rates were $76.3 \%$ and $71.6 \%$ in Group II and $88.3 \%$ and $79.8 \%$ in Group III, respectively ( $P=0.067$ and 0.247$)$. In subgroup analysis, the 5-year DFS rates tended to be lower in Group II (71.6\%) than in Group IIIA (79.7\%) and higher than those in Group IIIB (61.4\%).

Conclusion: $\mathrm{VI}$ is a prognostic factor as significant as LNM and may be regarded as a stronger prognostic factor than $\mathrm{N} 1$ stage in non-metastatic colon cancer. Furthermore, a potential association was observed between VI and recurrence patterns, such as early recurrence and distant metastasis.

\section{Background}

Colon cancer is one of the most common cancers in the world [1]. Standard treatment for non-metastatic colon cancer is curative resection, followed by adjuvant chemotherapy, in selected patients $[2,3]$. The survival benefit of adjuvant chemotherapy in patients with stage III has been well established [2,3]. Although guidelines recommend adjuvant chemotherapy for stage II colon cancer patients with one or more of high-risk features, it is often omitted in the clinical setting [2, 3]. High-risk features are defined as T4 tumors, poorly differentiated tumors, positive margin involvement, $<12$ lymph nodes (LNs) examined, obstruction, perforation, perineural invasion, lymphatic invasion, and vascular invasion $(\mathrm{VI})[2,3]$.

Distant metastasis is known to occur through vascular and lymphatic channels in colon cancer [4-9]. However, the clinicopathological staging system categorizes non-metastatic colon cancer into stage I-II and stage III, depending on the presence of lymph node metastasis (LNM) in the lymphatic pathway [10]. Such clinicopathological staging system is considered a strong predictor of the long-term oncological outcomes. On the other hand, there is no other way to assess the spread of cancer cells through the vascular channel than evaluating vascular invasion around the tumor, and this is not a factor that determines the stage. For this reason, the impact of VI on oncological outcomes has been underestimated as compared to that of LNM in the clinical setting. Conversely, based on the fact that the vascular system does not have a gateway like LN, we hypothesized that the tumor cells would spread 
through the vascular channel more aggressively and faster than through the lymphatic system. Several studies have shown that $\mathrm{VI}$ is a poor prognostic factor in colon cancer [11-14]. However, there were few studies that compared the prognostic impact of VI and LNM.

This study aimed to evaluate the prognostic impact of VI in comparison with that of LNM in stage I-III colon cancer without distant metastasis.

\section{Methods}

\section{Patients and data collection}

Patients who underwent surgery for primary colon carcinoma between March 2004 and December 2015 at Incheon St. Mary's Hospital, College of Medicine, The Catholic University of Korea, were included in this study $(n=905)$. Patients without data on VI were excluded $(n=14)$. We also excluded patients with intra-mucosal carcinoma $(n=27)$ and those who had a synchronous malignancy at the time of diagnosis or recurrence within 90 days after surgery $(n=71)$. Finally, 793 patients with stage I-III colon cancer were enrolled. This study was conducted by retrospectively reviewing the data, and the follow-up was completed in August 2018.

Patients demographics, clinicopathological characteristics, recurrence, and survival data were collected from the hospital's colon cancer patient registry. Patients with comorbidities were classified according to the American Society of Anesthesiologists (ASA) score. Right-sided colon was defined as cecum, ascending colon, hepatic flexure colon, and transverse colon. Left-sided colon was defined as splenic flexure colon, descending colon, sigmoid colon, and recto-sigmoid colon above the peritoneal reflection.

Pathological stage was classified according to the Seventh American Joint Cancer Committee TNM classification system [10]. In addition to VI, we recorded lymphatic invasion, perineural invasion, number of examined LNs, and histological grade as high-risk features. A favorable histological grade was defined as well or moderately differentiated adenocarcinoma. A poor histological grade was defined as poorly differentiated adenocarcinoma, mucinous carcinoma, or signet ring cell carcinoma. Hematoxylin and eosin (H\&E) staining was routinely used to assess the presence of VI.

This study was approved by the Institutional Review Board of the Ethics Committee of the College of Medicine, The Catholic University of Korea (OC19RESI0035). A statement of informed consent was obtained from all patients, and the procedures were in accordance with the ethical standards of the committee responsible for human experimentation and with the Helsinki Declaration, 1975, as revised in 1983. All patient records were anonymized and deidentified before the analysis.

\section{Study design}

The patients were divided into four groups depending on the presence of VI and LNM, regardless of TNM stage. Group I included patients without VI and LNM (VI-/LNM-); Group II, patients with VI and without LNM (VI+/LNM-); Group III, patients without VI and with LNM (VI-/LNM+); and Group IV, those with both VI 
and LNM (VI+/LNM+). Subsequently, we subdivided Group III into Group IIIA and Group IIIB according to N stage. Group IIIA included patients without VI and with N1 stage (metastasis in 1-3 regional LNs); and Group IIIB, those without VI and with N2 stage (metastasis in 4 or more regional LNs)

\section{Follow-up schedule and clinical outcomes}

Surveillance was performed in patients with colon cancer every 3-6 months until 2 years after surgery, and then every 6-12 months until 5 years after surgery. Tumor markers including carcinoembryonic antigen and carbohydrate antigen $19-9$, abdominopelvic computed tomography (CT), and chest CT were performed according to the surveillance schedule. Adjuvant chemotherapy was recommended for all patients with stage III and for those with stage II who had at least one of the high-risk features. The decision to undergo chemotherapy was made taking into consideration the patient's performance status and their consent.

The primary outcome was disease-free survival (DFS), which was defined as the interval from the date of surgery until the date of disease recurrence detection by radiological or pathological examination or, in case of no recurrence, until the last follow-up date. Overall survival (OS) was calculated from the date of surgery until either the date of death or that of the last follow-up. A subgroup analysis was performed, including only Group II (VI+/LNM-) and Group III (VI-/LNM+).

\section{Statistical analyses}

The categorical variables of the groups were compared using the chi-square or Fisher's exact test. DFS and OS rates were calculated using the Kaplan-Meier method, and survival curves were compared among the groups using the log-rank test. The univariate prognostic significance of variables was determined using the Cox proportional hazard model. Variables that were significantly related to survival rate in the univariate analysis were subsequently included in the multivariate analysis employing the Cox multiple regression model. All statistical analyses were performed using SPSS software for Windows (version 25.0; IBM Corp., Armonk, NY, USA). Two-tailed $P$-values of less than 0.05 were considered to indicate statistical significance.

\section{Results}

\section{Baseline characteristics related to vascular invasion}

A total of 793 patients with stages I-III colon cancer were included during this study period. Median follow-up duration was 48 months (interquartile range 29-65). The mean age of the patients was $63.6 \pm$ 12.5 years, the male-to-female ratio was $1.18: 1$, and 131 patients $(16.5 \%)$ had an ASA score $\geq 3$. Tumors were localized to the right-sided colon in $304(38.3 \%)$ and to the left-sided colon in 489 patients (61.7\%). The operation was performed by the laparoscopic approach in 738 (93.1\%) and by the conventional approach in 55 patients (6.9\%). Adjuvant chemotherapy was administered to 575 (72.5\%), and recurrence was observed in 153 patients (19.3\%). 
Vascular invasion was present in 109 patients (13.7\%). The clinicopathological characteristics of patients were compared according to the presence or absence of $\mathrm{VI}$ (Table 1). Patients with VI demonstrated significantly higher rates of lymphatic invasion $(89.0 \%$ vs. $38.7 \% ; P<0.001)$, perineural invasion $(60.6 \%$ vs. $32.9 \%$; $P<0.001$ ), poor histological grade $(20.2 \%$ vs. $7.9 \% ; P<0.001)$, T4 tumor $(37.6 \%$ vs. $15.5 \% ; P<$ $0.001)$, and LNM $(75.2 \%$ vs. $47.8 \% ; P<0.001)$ than those without VI. The adjuvant chemotherapy rate was higher in patients with $\mathrm{VI}$ than in those without $\mathrm{VI}(82.6 \% \mathrm{vs} .70 .9 \% ; P=0.011)$. The recurrence rate was higher in patients with $\mathrm{VI}$ than in those without $\mathrm{VI}(29.4 \%$ vs. $17.7 \% ; P=0.004)$. However, local recurrence rates were not different between patients with and without VI (2.8\% vs. $2.0 \% ; P=0.718)$. 
Table 1

Patient's Clinico-pathological characteristics according to the presence of vascular invasion (VI)

\begin{tabular}{|c|c|c|c|c|}
\hline Variables & $\begin{array}{l}\text { Total patients } \\
(\mathrm{N}=793)\end{array}$ & $\begin{array}{l}\text { no } \mathrm{VI}(\%) \\
(\mathrm{N}=684,86.3 \%)\end{array}$ & $\begin{array}{l}\text { VI (\%) } \\
(\mathrm{N}=109,13.7 \%)\end{array}$ & $P$-value \\
\hline Age $>65$ years & $397(50.1)$ & $341(49.9)$ & $56(51.4)$ & 0.768 \\
\hline Gender, female & $363(45.8)$ & $320(46.8)$ & $43(39.4)$ & 0.153 \\
\hline ASA score, $\geq 3$ & $131(16.5)$ & $111(16.2)$ & $20(18.3)$ & 0.580 \\
\hline Tumor location & & & & 0.220 \\
\hline Right-sided & $304(38.3)$ & 268(39.2) & $36(33.0)$ & \\
\hline Left-sided & $489(61.7)$ & $416(60.8)$ & $73(67.0)$ & \\
\hline Surgical approach & & & & 0.858 \\
\hline Laparoscopic & 738(93.1) & $637(93.1)$ & 101(92.7) & \\
\hline Conventional & $55(6.9)$ & $47(6.9)$ & $8(7.3)$ & \\
\hline Combined resection, yes & 109(13.7) & $96(14.0)$ & 13(11.9) & 0.553 \\
\hline T4 tumor & 147(18.5) & $106(15.5)$ & $41(37.6)$ & $<0.001$ \\
\hline LN metastasis, yes & $409(51.6)$ & $327(47.8)$ & $82(75.2)$ & $<0.001$ \\
\hline Stage & & & & $<0.001$ \\
\hline I & $54(6.8)$ & $52(7.6)$ & $2(1.8)$ & \\
\hline II & $330(41.6)$ & $305(44.6)$ & $25(22.9)$ & \\
\hline III & $409(51.6)$ & $327(47.8)$ & $82(75.2)$ & \\
\hline LN harvest, $<12$ & $71(9.0)$ & $61(8.9)$ & $10(9.2)$ & 0.931 \\
\hline Histological grade, poor & $76(9.6)$ & $54(7.9)$ & $22(20.2)$ & $<0.001$ \\
\hline Lymphatic invasion, yes & $362(45.6)$ & $265(38.7)$ & $97(89.0)$ & $<0.001$ \\
\hline Perineural invasion, yes & 291(36.7) & $225(32.9)$ & $66(60.6)$ & $<0.001$ \\
\hline Adjuvant chemotherapy, yes & $575(72.5)$ & $485(70.9)$ & $90(82.6)$ & 0.011 \\
\hline Recurrence, yes & 153(19.3) & $121(17.7)$ & $32(29.4)$ & 0.004 \\
\hline Local recurrence, yes & $17(2.1)$ & $14(2.0)$ & $3(2.8)$ & 0.718 \\
\hline
\end{tabular}


Of the 793 patients, 357 (45.0\%) were included in Group I, 27 (3.4\%) in Group II, 327 (41.2\%) in Group III, and $82(10.3 \%)$ in Group IV. The clinicopathological characteristics of patients are listed according to their respective groups in Table 2. Group IV (VI+/LNM+) had the highest rates of T4 tumor $(P<0.001)$, poor histological grade $(P<0.001)$, lymphatic invasion $(P<0.001)$, and perineural invasion $(P<0.001)$ among the groups. The recurrence rate was the highest in Group IV (30.5\%) and the lowest in Group I (11.5\%) $(P$ $<0.001)$. There was no difference in local recurrence rates among the groups $(P=0.388)$. 
Table 2

Patient's Clinico-pathological characteristics according to the groups

\begin{tabular}{|c|c|c|c|c|c|c|}
\hline Variables & $\begin{array}{l}\text { Group I } \\
\text { VI-, LNM- } \\
(\mathrm{N}=357)\end{array}$ & $\begin{array}{l}\text { Group II } \\
\text { VI+, } \\
\text { LNM- } \\
(\mathrm{N}=27)\end{array}$ & $\begin{array}{l}\text { Group III } \\
\text { VI-, LNM+ } \\
(\mathrm{N}=327)\end{array}$ & $\begin{array}{l}\text { Group } \\
\text { IV } \\
\text { Vl+, } \\
\text { LNM+ } \\
(\mathrm{N}=82)\end{array}$ & $\begin{array}{l}P \text { - } \\
\text { value* }\end{array}$ & $\begin{array}{l}P- \\
\text { value** }\end{array}$ \\
\hline Age $>65$ years & $180(50.4)$ & 18(66.7) & $161(49.2)$ & $38(46.3)$ & 0.316 & 0.082 \\
\hline Gender, female & $152(42.6)$ & $8(29.6)$ & $168(51.4)$ & $35(42.7)$ & 0.033 & 0.030 \\
\hline ASA score, $\geq 3$ & $56(15.7)$ & $6(22.2)$ & $55(16.8)$ & $\begin{array}{l}14 \\
(17.1)\end{array}$ & 0.836 & 0.435 \\
\hline Tumor location & & & & & 0.518 & 0.174 \\
\hline Right-sided & $140(39.2)$ & $7(25.9)$ & $128(39.1)$ & $29(35.4)$ & & \\
\hline Left-sided & $217(60.8)$ & $20(74.1)$ & 199(60.9) & $53(64.6)$ & & \\
\hline Surgical approach & & & & & 0.422 & 1.000 \\
\hline Laparoscopic & $338(94.7)$ & 25(92.6) & 299(91.4) & $76(92.7)$ & & \\
\hline Conventional & $19(5.3)$ & $2(7.4)$ & $28(8.6)$ & $6(7.3)$ & & \\
\hline Combined resection, yes & $45(12.6)$ & $2(7.4)$ & $51(15.6)$ & 11(13.4) & 0.520 & 0.399 \\
\hline T4 tumor & $30(8.4)$ & $6(22.2)$ & $76(23.2)$ & $35(42.7)$ & $<.001$ & 0.904 \\
\hline Stage & & & & & $\begin{array}{l}<.001 \\
0.001\end{array}$ & $<0.001$ \\
\hline I & $52(14.6)$ & $2(7.4)$ & 0 & 0 & & \\
\hline ॥ & $305(85.4)$ & $25(92.6)$ & 0 & 0 & & \\
\hline III & 0 & 0 & $327(100)$ & $82(100)$ & & \\
\hline LN harvest, $<12$ & $39(10.9)$ & $4(14.8)$ & $22(6.7)$ & $6(7.3)$ & 0.165 & 0.125 \\
\hline Histological grade, poor & $18(5.0)$ & $2(7.4)$ & $36(11.0)$ & $20(24.4)$ & $<_{0.001}$ & 0.753 \\
\hline
\end{tabular}

$\mathrm{VI}$, vascular invasion; LNM, lymph node metastasis; ASA, American Society of Anesthesiologist; T, tumor; LN, lymph node.

*P-value comparing all groups.

**P-value comparing only group II (VI+/LNM-) and group III (VI-/LNM+).

Proportion are presented for categorical data. (\%) 


\begin{tabular}{|c|c|c|c|c|c|c|}
\hline Variables & $\begin{array}{l}\text { Group I } \\
\text { VI-, LNM- } \\
(\mathrm{N}=357)\end{array}$ & $\begin{array}{l}\text { Group II } \\
\text { Vl+, } \\
\text { LNM- } \\
(\mathrm{N}=27)\end{array}$ & $\begin{array}{l}\text { Group III } \\
\text { VI-, LNM+ } \\
(\mathrm{N}=327)\end{array}$ & $\begin{array}{l}\text { Group } \\
\text { IV } \\
\text { Vl+, } \\
\text { LNM+ } \\
(\mathrm{N}=82)\end{array}$ & $\begin{array}{l}P- \\
\text { value* }\end{array}$ & $\begin{array}{l}P \text { - } \\
\text { value** }\end{array}$ \\
\hline Lymphatic invasion, yes & $67(18.8)$ & 21(77.8) & 198(60.6) & 76(92.7) & $<.001$ & 0.077 \\
\hline Perineural invasion, yes & $93(26.1)$ & $12(44.4)$ & $132(40.4)$ & $54(65.9)$ & $\dot{0} 001$ & 0.678 \\
\hline $\begin{array}{l}\text { Adjuvant systemic } \\
\text { chemotherapy, yes }\end{array}$ & $218(61.1)$ & $21(77.8)$ & $267(81.7)$ & $69(84.1)$ & $<.001$ & 0.619 \\
\hline Recurrence, yes & $41(11.5)$ & $7(25.9)$ & $80(24.5)$ & $25(30.5)$ & $<_{0.001}$ & 0.865 \\
\hline Local recurrence, yes & $5(1.4)$ & $0(0.0)$ & $9(2.8)$ & $3(3.7)$ & 0.388 & 1.000 \\
\hline \multicolumn{7}{|c|}{$\begin{array}{l}\text { VI, vascular invasion; LNM, lymph node metastasis; ASA, American Society of Anesthesiologist; T, } \\
\text { tumor; LN, lymph node. }\end{array}$} \\
\hline \multicolumn{7}{|c|}{$\star P$-value comparing all groups. } \\
\hline \multicolumn{7}{|c|}{ **P-value comparing only group II (VI+/LNM-) and group III (VI-/LNM+). } \\
\hline Proportion are presented & gorical dat & & & & & \\
\hline
\end{tabular}

No significant difference was observed between Group II (VI+/LNM-) and Group III (VI-/LNM+), except for the gender ratio; patients in Group II were predominantly male $(P=0.030)$. Adjuvant chemotherapy was given to $77.8 \%$ and $81.7 \%$ of patients in Groups II and III, respectively $(P=0.619)$. Recurrence rates were $25.9 \%$ in Group II and $24.5 \%$ in Group III $(P=0.865)$.

\section{Survival outcomes}

The outcomes of the univariate and multivariate analyses to identify significant prognostic factors for DFS and OS are shown in Tables 3 and 4, respectively. The univariate analysis showed that both VI (hazard ratio [HR] 1.98; 95\% confidence interval [Cl] 1.34-2.92) and LNM (HR 2.26; 95\% Cl 1.60-3.17) were significant prognostic factors for poor DFS. Additionally, DFS was significantly worse in patients with T4 tumor, poor histological grade, lymphatic invasion, and perineural invasion. Patients in Groups II, III, and IV had poorer DFS than those in Group I. Multivariate analysis revealed that Group II (HR 2.34; $95 \%$ Cl 1.01-5.41), Group III (HR 1.91; 95\% Cl 1.26-2.89), Group IV (HR 2.34; 95\% Cl 1.33-4.14), poor histological grade (HR 1.66; 95\% Cl 1.07-2.59), and T4 tumors (HR 2.08; 95\% Cl 1.44-3.01) were independently associated with poor DFS. Lymphatic invasion and perineural invasion were not detected as significant independent prognostic factors for DFS. 
Table 3

Disease-free survival in stage I-III colon cancer patients

\begin{tabular}{|c|c|c|c|c|}
\hline \multirow[b]{2}{*}{ Variables } & \multicolumn{2}{|c|}{ Univariate analysis } & \multicolumn{2}{|c|}{ Multivariate analysis } \\
\hline & $\mathrm{HR}(95 \% \mathrm{Cl})$ & $P$ & $\mathrm{HR}(95 \% \mathrm{Cl})$ & $P$ \\
\hline Age $\geq 65$ & $1.29(0.94-1.77)$ & 0.119 & & \\
\hline Gender, female & $0.90(0.65-1.24)$ & 0.512 & & \\
\hline ASA score, $\geq 3$ & $1.24(0.82-1.89)$ & 0.304 & & \\
\hline Tumor location, left-sided & $0.98(0.71-1.36)$ & 0.912 & & \\
\hline T4 tumor & $2.75(1.96-3.85)$ & $<0.001$ & $2.08(1.44-3.01)$ & $<0.001$ \\
\hline LN metastasis, yes & $2.26(1.60-3.17)$ & $<0.001$ & & \\
\hline LN harvest, $<12$ & $1.01(0.57-1.79)$ & 0.970 & & \\
\hline Histological grade, poor & $2.05(1.32-3.16)$ & 0.001 & $1.66(1.07-2.59)$ & 0.024 \\
\hline Vl, yes & $1.98(1.34-2.92)$ & 0.001 & & \\
\hline Lymphatic invasion, yes & $1.89(1.37-2.61)$ & $<0.001$ & $1.04(0.70-1.55)$ & 0.847 \\
\hline Perineural invasion, yes & $1.52(1.11-2.09)$ & 0.010 & $1.09(0.77-1.56)$ & 0.617 \\
\hline Adjuvant systemic chemotherapy, yes & $0.84(0.58-1.21)$ & 0.340 & & \\
\hline \multicolumn{5}{|l|}{ Group } \\
\hline (VI-, LNM-) & Reference & & Reference & \\
\hline$(\mathrm{VI}+$, LNM-) & $2.78(1.25-6.20)$ & 0.012 & $2.34(1.01-5.41)$ & 0.048 \\
\hline$(\mathrm{VI}-$, LNM+) & $2.31(1.59-3.37)$ & $<0.001$ & $1.91(1.26-2.89)$ & 0.002 \\
\hline$(\mathrm{VI}+, \mathrm{LNM}+)$ & $3.29(2.00-5.42)$ & $<0.001$ & $2.34(1.33-4.14)$ & 0.003 \\
\hline
\end{tabular}


Table 4

Overall survival in stage I-III colon cancer patients

\begin{tabular}{|c|c|c|c|c|}
\hline \multirow[b]{2}{*}{ Variables } & \multicolumn{2}{|c|}{ Univariate analysis } & \multicolumn{2}{|c|}{ Multivariate analysis } \\
\hline & $\mathrm{HR}(95 \% \mathrm{Cl})$ & $P$ & $\mathrm{HR}(95 \% \mathrm{Cl})$ & $P$ \\
\hline Age $\geq 65$ & $1.96(1.29-3.00)$ & 0.002 & $1.53(0.97-2.39)$ & 0.066 \\
\hline Gender, female & $0.67(0.43-1.02)$ & 0.062 & & \\
\hline ASA score, $\geq 3$ & $2.07(1.30-3.30)$ & 0.002 & $1.64(1.01-2.66)$ & 0.044 \\
\hline Tumor location, left-sided & $0.94(0.61-1.43)$ & 0.754 & & \\
\hline T4 tumor & $2.59(1.67-4.01)$ & $<0.001$ & $1.98(1.21-3.23)$ & 0.007 \\
\hline LN metastasis, yes & $1.87(1.22-2.88)$ & 0.004 & & \\
\hline LN harvest, $<12$ & $1.62(0.88-2.97)$ & 0.122 & & \\
\hline Histological grade, poor & $2.54(1.52-4.26)$ & $<0.001$ & $2.11(1.24-3.61)$ & 0.006 \\
\hline Vl, yes & $2.21(1.37-3.58)$ & 0.001 & & \\
\hline Lymphatic invasion, yes & $1.79(1.18-2.72)$ & 0.006 & $1.21(0.71-2.06)$ & 0.481 \\
\hline Perineural invasion, yes & $1.38(0.92-2.10)$ & 0.124 & & \\
\hline Adjuvant systemic chemotherapy, yes & $0.43(0.28-0.65)$ & $<0.001$ & $0.33(0.20-0.53)$ & $<0.001$ \\
\hline \multicolumn{5}{|l|}{ Group } \\
\hline (VI-, LNM-) & Reference & & Reference & \\
\hline$(\mathrm{VI}+$, LNM-) & $2.03(0.71-5.79)$ & 0.185 & $1.72(0.57-5.22)$ & 0.340 \\
\hline$(\mathrm{VI}-$, LNM+) & $1.71(1.06-2.76)$ & 0.029 & $1.66(0.85-3.27)$ & 0.141 \\
\hline$(\mathrm{VI}+, \mathrm{LNM}+)$ & $3.26(1.81-5.90)$ & $<0.001$ & $2.92(1.40-6.08)$ & 0.004 \\
\hline
\end{tabular}

Both VI (HR 2.21; 95\% Cl 1.37-3.58) and LNM (HR 1.87; 95\% Cl 1.22-2.88) were significant prognostic factors for poor OS in the univariate analysis. Additionally, OS rates were significantly worse in older patients and in those with a high ASA score ( $\geq 3)$, T4 tumors, poor histological grade, and lymphatic invasion. Patients in Groups III and IV showed poorer OS than those in Group I. Patients who received adjuvant chemotherapy showed favorable prognosis with regard to OS. In the multivariate analysis, high ASA score (HR 1.64; 95\% Cl 1.01-2.66), T4 tumor (HR 1.98; 95\% Cl 1.21-3.23), poor histological grade (HR 2.11; 95\% Cl 1.24-3.61), and Group IV (HR 2.92; 95\% Cl 1.40-6.08) were independently associated with poor OS. Adjuvant chemotherapy was an independent favorable prognostic factor for OS (HR 0.33 ; 95\% Cl 0.20-0.53). 
The negative impacts of VI and LNM on DFS and OS were evaluated using Kaplan-Meier curves (Fig. 1). Patients in both Group II (VI+/LNM-) and Group III (VI-/LNM+) had poorer prognosis than those in Group I (VI-/LNM-). Group IV (VI+/LNM+) showed the worst prognosis among the groups regarding DFS and OS $(P<0.001$ and $P<0.001)$. The 5-year DFS rates were $86.6 \%$ in Group I, $71.6 \%$ in Group II, $72.5 \%$ in Group III, and $64.4 \%$ in Group IV. The 5-year OS rates were $91.9 \%$ in Group I, $80.6 \%$ in Group II, $83.8 \%$ in Group III, and $76.2 \%$ in Group IV.

\section{Subgroup analysis}

A subgroup analysis was performed, including only Groups II and III, to compare prognostic impact of VI and LNM. No significant differences in DFS and OS were observed between Groups II and III $(P=0.637$ and $P=0.697$ ) (Fig. 2a and 2b). The 1-year DFS rates were $76.3 \%$ in Group II and $88.3 \%$ in Group III ( $P=$ 0.067). The 2-year DFS rates were $71.6 \%$ in Group II and $79.8 \%$ in Group III ( $P=0.247)$. Otherwise, the 5year DFS rates were almost the same between the two groups (71.6\% in Group II and $72.5 \%$ in Group III).

Subsequently, Group III was subdivided into IIIA (VI-/N1) and IIIB (VI-/N2) based on N stage to compare oncological outcomes with Group II (VI+/NO). The 5-year DFS rates were $71.6 \%$ in Group II, 79.7\% in Group IIIA, and 61.4\% in Group IIIB (Fig. 2c). The 5-year OS rates were $80.6 \%$ in Group II, $87.1 \%$ in Group IIIA, and $78.1 \%$ in Group IIIB (Fig. 2d). The Kaplan-Meier curve showed a tendency for DFS and OS to be shorter in Group II than in Group IIIA (DFS, HR 1.72, 95\% Cl 0.76-3.87; OS, HR 1.56, 95\% Cl 0.54-4.58) and a tendency for those to be longer in Group II than in Group IIIB (DFS, HR 0.77, 95\% Cl 0.35-1.71; OS, HR 0.88, 95\% Cl 0.30-2.58).

\section{Analysis of recurrence type}

No differences in recurrence types such as distant metastasis, local recurrence, or recurrence in the liver, lung, or peritoneum were observed between recurrent patients in Groups II and III (Table 5). However, all recurrences were distant metastasis in Group II. Otherwise, local recurrence was observed in 9 patients $(11.3 \%)$ in Group III. 
Table 5

Recurrence types of recurrent patients in groups II and III

\begin{tabular}{|llll|}
\hline Variables & $\begin{array}{l}\text { Group II } \\
\text { Vl+, LNM- } \\
\end{array}$ & $\begin{array}{l}\text { Group III } \\
\text { VI-, LNM+ }\end{array}$ & P-value \\
& $\mathbf{N}=\mathbf{7})$ & $\mathbf{( N = 8 0 )}$ & \\
\hline Liver metastasis, yes & $3(42.9)$ & $33(41.3)$ & 1.000 \\
\hline Lung metastasis, yes & $2(28.6)$ & $26(32.5)$ & 1.000 \\
\hline Peritoneal metastasis, yes & $2(28.6)$ & $17(21.3)$ & 0.644 \\
\hline Distant metastasis, yes & $7(100.0)$ & $75(93.8)$ & 1.000 \\
\hline Local recurrence, yes & $0(0.0)$ & $9(11.3)$ & 1.000 \\
\hline VI, vascular invasion; LNM, lymph node metastasis. \\
\hline \multicolumn{4}{|l}{ Proportion are presented for categorical data. (\%) } \\
\hline
\end{tabular}

\section{Discussion}

In colon cancer, the TNM staging is very simple because LNM is the only criterion for stage III [10]. However, overemphasis on LNM in the colon cancer TNM staging system is controversial. Many studies have reported the prognostic impact of high-risk features beyond LNM [11-23]. One study showed the relationship between the number of high-risk features and prognosis, demonstrating that 5-year OS rate was less than $20 \%$ in patients with stage II colon cancer with four or more high-risk features [18]. These studies suggest that high-risk features may have a similar or worse prognosis than LNM.

To the best of our knowledge, this is one of the few studies to compare the prognostic impact of $\mathrm{Vl}$, which is one of the high-risk features of stage II, with that of LNM, the only stage III criterion in colon cancer. We divided patients into the groups depending on the presence of VI and LNM, regardless of the TNM stage. We showed that VI was a poor prognostic factor in non-metastatic colon cancer. Otherwise, there was no significant difference between the prognostic impacts of VI and LNM. Furthermore, although statistical significance was not reached, the 5-year DFS rate in VI+/N0 patients (71.6\%) was lower than that in $\mathrm{VI} / \mathrm{N} 1$ patients $(79.7 \%)$ and higher than that in $\mathrm{VI} / \mathrm{N} 2$ patients $(61.4 \%)$. These findings suggest that the prognostic impact of VI may be located somewhere between those of N1 and N2 in the TNM staging system.

Another interesting point of this study was the recurrence pattern. Seven recurrences occurred in $\mathrm{VI+/LNM-patients,} \mathrm{and} \mathrm{all} 7$ (100\%) occurred within 2 years. Of the 7 recurrences, 6 cases $(85.7 \%)$ occurred within 1 year and 1 case (14.3\%) occurred 24 months after the surgery. In VI-/LNM + patients, there were 36 (45.0\%) recurrences within 1 year and 61 (76.3\%) recurrences within 2 years among the 80 recurrences in total. The 1-year DFS rates were $76.3 \%$ in VI+/LNM- patients and $88.3 \%$ in VI-/LNM + 
patients $(P=0.067)$, and the 2-year DFS rates were $71.6 \%$ in VI+/LNM- patients and $79.8 \%$ in VI-/LNM + patients $(P=0.247)$. In addition, all recurrences in VI+/LNM- patients were distant metastasis. Otherwise, $11.3 \%$ of the recurrence in $\mathrm{VI}-/ \mathrm{LNM}+$ patients was local recurrence. Although, these findings did not reach statistical significance, $\mathrm{VI}+/ \mathrm{LNM}$ - patients tended to be associated with early recurrence and distant metastasis compared to VI-/LNM + patients. We even guaranteed that stage II colon cancer patients with $\mathrm{VI}$ received adequate adjuvant chemotherapy in the present study. The proportion of patients who underwent chemotherapy in $\mathrm{VI}+/$ LNM- patients was $77.8 \%$, which was comparable to that in $\mathrm{VI}$-/LNM + patients (81.7\%).

Distant metastasis is the most common cause of death in patients with cancer, [24, 25], and it is known to occur through vascular and lymphatic channels [4-9]. Lymphatic drainage occurs in the order of epicolic/paracolic LN, intermediate LN, and apical LN in colon cancer [26]. The association between the location of a regional LNM and disease recurrence has been reported [27, 28]. For these reasons, a complete mesocolic excision (CME), including the apical $L N$ and central vessel ligation (CVL), is considered the standard procedure in colon cancer surgery. Indeed, many studies have reported that CME and CVL contributed to better survival outcomes [29-31]. When surgeons perform adequate CME and CVL procedures, the risk for metastasis through lymphatic channels can be reduced. For example, in stage III colon cancer without apical LNM, theoretically, the possibility of distant metastasis through lymphatic channels is blocked by surgery with CME and CVL if there is no skip metastasis of LN. In contrast, the vascular system differs from the lymphatic system because it does not have a gateway like LNs do. Based on these facts, we hypothesized that tumor cell dissemination would be more aggressive and faster when tumor cells were transported through the vascular system than through the lymphatic system. In the present study, we performed CME and CVL in all patients and demonstrated that VI not only was a poor prognostic factor similar to LNM but also may be an indicator of earlier recurrence more than LNM.

The present study had several limitations. First, as this study was retrospective, inherent and unintentional selection bias cannot be dismissed. However, the selection bias was minimized because the clinicopathological factors, which can affect the prognosis, were not different between VI+/LNM- and $\mathrm{VI}-/ \mathrm{LNM}+$ patients. Even the proportions of patients who received adjuvant chemotherapy in VI+/LNMand VI-/LNM + groups were comparable. Second, the sample size was small. The 1-year and 2-year DFS rates in VI+/LNM- patients tended to be lower than those in VI-/LNM + patients. Furthermore, VI tended to be a stronger prognostic factor than metastasis in 1-3 regional LNs. However, these differences were not significant. Therefore, large-scale multicenter studies are needed to clarify the prognostic impact of $\mathrm{VI}$ compared to that of LNM. Finally, the detection rate of VI was low in this study (13.7\%). Recent studies have reported the detection rates of $\mathrm{VI}$ ranging from $19-34 \%[11-13,15,16,18]$. This difference may be due to the staining method. One study investigated the detection rate of $\mathrm{VI}$ in 93 patients with $\mathrm{T} 3$ or T4 colorectal cancer and reported that it increased from $15.1 \%$ in the original pathological report when using H\&E staining to $48.4 \%$ when elastic stain was used [32]. Another study showed that the use of elastic stain increased the VI detection rate from $19.6-46.4 \%$, compared with routine H\&E staining by 
gastrointestinal pathologists [33]. As our study only used H\&E staining, this may have caused lower VI detection rates in the results.

\section{Conclusion}

In conclusion, we demonstrated that $\mathrm{VI}$ is a prognostic factor as significant as LNM and may be a stronger prognostic factor than $\mathrm{N} 1$ stage in non-metastatic colon cancer. Furthermore, the result provided the first insights into a potential association between VI and recurrence patterns, such as early recurrence and distant metastasis. Therefore, this study suggests that adjuvant chemotherapy should be considered in stage II colon cancer with VI. A multicenter large-scale study using an advanced staining method would help to clarify the prognostic impact of VI.

\section{List Of Abbreviations}

ASA, American Society of Anesthesiologists; CME, complete mesocolic excision; CT, computed tomography; CVL, central vessel ligation; DFS, Disease-free survival; LN, lymph nodes; LNM, lymph node metastasis; OS, overall survival; $\mathrm{VI}$, vascular invasion

\section{Declarations}

\section{Ethics approval and consent to participate}

This study was approved by the Institutional Review Board of the Ethics Committee of the College of Medicine, The Catholic University of Korea (OC19RESI0035). A statement of informed consent was obtained from all patients, and the procedures were in accordance with the ethical standards of the responsible committee on human experimentation and with the Helsinki Declaration, 1975, as revised in 1983. All patient records were anonymized and de-identified before analysis.

\section{Consent for publication}

Not applicable

\section{Availability of data and materials}

The datasets used and/or analysed during the current study are available from the corresponding author on reasonable request.

\section{Competing interests}

The authors declare that they have no competing interests.

\section{Funding}


This research did not receive any specific grant from funding agencies in the public, commercial, or notfor-profit sectors.

\section{Authors' contributions}

Conceptualization: YS Lee; Data curation: JH Kim, YS Lee; Formal analysis: JH Bae; Investigation: JH Bae, CS Lee, SR Han, JH Kim, YS Lee; Methodology: JH Bae, BH Kye, YS Lee; Project administration: JH Bae, YS Lee; Resources: JH Bae, JH Kim, YS Lee; Software: JH Bae; Supervision: BH Kye, IK Lee, YS Lee; Validation: BH Kye, IK Lee, YS Lee; Visualization: JH Bae, YS Lee; Writing - original draft: JH Bae; Writing review \& editing: YS Lee

\section{Acknowledgments}

We would like to thank Editage (https://www.editage.co.kr) for providing assistance in editing the language of the manuscript.

\section{References}

1. Siegel RL, Miller KD, Jemal A. Cancer statistics, 2019. CA Cancer J Clin. 2019;69:7-34.

2. Benson AB 3rd, Venook AP, Cederquist L, Chan E, Chen YJ, Cooper HS, et al. Colon Cancer, Version 1.2017, NCCN Clinical Practice Guidelines in Oncology. J Natl Compr Canc Netw. 2017;15:370-98.

3. Labianca R, Nordlinger B, Beretta GD, Mosconi S, Mandala M, Cervantes A, et al. Early colon cancer: ESMO Clinical Practice Guidelines for diagnosis, treatment and follow-up. Ann Oncol. 2013;24(Suppl 6):vi64-72.

4. Springfield DS. Mechanisms of metastasis. Clin Orthop Relat Res. 1982:15-9.

5. Royston D, Jackson DG. Mechanisms of lymphatic metastasis in human colorectal adenocarcinoma. J Pathol. 2009;217:608-19.

6. Ferris RL, Lotze MT, Leong SP, Hoon DS, Morton DL. Lymphatics, lymph nodes and the immune system: barriers and gateways for cancer spread. Clin Exp Metastasis. 2012;29:729-36.

7. Witte MH, Dellinger MT, McDonald DM, Nathanson SD, Boccardo FM, Campisi CC, et al. Lymphangiogenesis and hemangiogenesis: potential targets for therapy. J Surg Oncol. 2011;103:489-500.

8. Holopainen T, Bry M, Alitalo K, Saaristo A. Perspectives on lymphangiogenesis and angiogenesis in cancer. J Surg Oncol. 2011;103:484-8.

9. Pantel K, Brakenhoff RH. Dissecting the metastatic cascade. Nat Rev Cancer. 2004;4:448-56.

10. Hari DM, Leung AM, Lee JH, Sim MS, Vuong B, Chiu CG, et al. AJCC Cancer Staging Manual 7th edition criteria for colon cancer: do the complex modifications improve prognostic assessment? J Am Coll Surg. 2013;217:181-90.

11. Betge J, Pollheimer MJ, Lindtner RA, Kornprat P, Schlemmer A, Rehak P, et al. Intramural and extramural vascular invasion in colorectal cancer: prognostic significance and quality of pathology 
reporting. Cancer. 2012;118:628-38.

12. Gibson KM, Chan C, Chapuis PH, Dent OF, Bokey L. Mural and extramural venous invasion and prognosis in colorectal cancer. Dis Colon Rectum. 2014;57:916-26.

13. Parnaby CN, Scott NW, Ramsay G, MacKay C, Samuel L, Murray Gl, et al. Prognostic value of lymph node ratio and extramural vascular invasion on survival for patients undergoing curative colon cancer resection. Br J Cancer. 2015;113:212-9.

14. Skancke M, Arnott SM, Amdur RL, Siegel RS, Obias VJ, Umapathi BA. Lymphovascular Invasion and Perineural Invasion Negatively Impact Overall Survival for Stage II Adenocarcinoma of the Colon. Dis Colon Rectum. 2019;62:181-8.

15. Petersen VC, Baxter KJ, Love SB, Shepherd NA. Identification of objective pathological prognostic determinants and models of prognosis in Dukes' B colon cancer. Gut. 2002;51:65-9.

16. Leijssen LGJ, Dinaux AM, Amri R, Taylor MS, Deshpande V, Bordeianou LG, et al. Impact of intramural and extramural vascular invasion on stage II-III colon cancer outcomes. J Surg Oncol. 2019;119:749-57.

17. Babcock BD, Aljehani MA, Jabo B, Choi AH, Morgan JW, Selleck MJ, et al. High-Risk Stage II Colon Cancer: Not All Risks Are Created Equal. Ann Surg Oncol. 2018;25:1980-5.

18. Amri R, England J, Bordeianou LG, Berger DL. Risk Stratification in Patients with Stage II Colon Cancer. Ann Surg Oncol. 2016;23:3907-14.

19. Cienfuegos JA, Martinez P, Baixauli J, Beorlegui C, Rosenstone S, Sola JJ, et al. Perineural Invasion is a Major Prognostic and Predictive Factor of Response to Adjuvant Chemotherapy in Stage I-II Colon Cancer. Ann Surg Oncol. 2017;24:1077-84.

20. Amri R, Bordeianou LG, Sylla P, Berger DL. Association of Radial Margin Positivity With Colon Cancer. JAMA Surg. 2015;150:890-8.

21. Liu Q, Luo D, An H, Zhang S, Cai S, Li Q, et al. Survival benefit of adjuvant chemotherapy for patients with poorly differentiated stage IIA colon cancer. J Cancer. 2019;10:1209-15.

22. Vergara-Fernandez O, Navarro-Navarro A, Rangel-Rios HA, Salgado-Nesme N, Reyes-Monroy JA, Velazquez-Fernandez D. Oncological Implications of Lymph Nodes Retrieval and Perineural Invasion in Colorectal Cancer: Outcomes from a Referral Center. Rev Invest Clin. 2018;70:291-300.

23. Chin CC, Wang JY, Changchien CR, Huang WS, Tang R. Carcinoma obstruction of the proximal colon cancer and long-term prognosis-obstruction is a predictor of worse outcome in TNM stage II tumor. Int J Colorectal Dis. 2010;25:817-22.

24. Edwards BK, Noone AM, Mariotto AB, Simard EP, Boscoe FP, Henley SJ, et al. Annual Report to the Nation on the status of cancer, 1975-2010, featuring prevalence of comorbidity and impact on survival among persons with lung, colorectal, breast, or prostate cancer. Cancer. 2014;120:1290 314.

25. Pachmayr E, Treese C, Stein U. Underlying Mechanisms for Distant Metastasis - Molecular Biology. Visc Med. 2017;33:11-20. 
26. Merrie AE, Phillips LV, Yun K, McCall JL. Skip metastases in colon cancer: assessment by lymph node mapping using molecular detection. Surgery. 2001;129:684-91.

27. Kobayashi H, Enomoto M, Higuchi T, Uetake H, lida S, Ishikawa T, et al. Clinical significance of lymph node ratio and location of nodal involvement in patients with right colon cancer. Dig Surg. 2011;28:190-7.

28. Liang JT, Lai HS, Huang J, Sun CT. Long-term oncologic results of laparoscopic D3 lymphadenectomy with complete mesocolic excision for right-sided colon cancer with clinically positive lymph nodes. Surg Endosc. 2015;29:2394-401.

29. Bertelsen CA, Neuenschwander AU, Jansen JE, Wilhelmsen M, Kirkegaard-Klitbo A, Tenma JR, et al. Disease-free survival after complete mesocolic excision compared with conventional colon cancer surgery: a retrospective, population-based study. Lancet Oncol. 2015;16:161-8.

30. Merkel S, Weber K, Matzel KE, Agaimy A, Gohl J, Hohenberger W. Prognosis of patients with colonic carcinoma before, during and after implementation of complete mesocolic excision. $\mathrm{Br} \mathrm{J}$ Surg. 2016;103:1220-9.

31. Storli KE, Sondenaa K, Furnes B, Nesvik I, Gudlaugsson E, Bukholm I, et al. Short term results of complete (D3) vs. standard (D2) mesenteric excision in colon cancer shows improved outcome of complete mesenteric excision in patients with TNM stages I-II. Tech Coloproctol. 2014;18:557-64.

32. Hwang C, Lee S, Kim A, Kim YG, Ahn SJ, Park DY. Venous Invasion in Colorectal Cancer: Impact of Morphologic Findings on Detection Rate. Cancer Res Treat. 2016;48:1222-8.

33. Kirsch R, Messenger DE, Riddell RH, Pollett A, Cook M, Al-Haddad S, et al. Venous invasion in colorectal cancer: impact of an elastin stain on detection and interobserver agreement among gastrointestinal and nongastrointestinal pathologists. Am J Surg Pathol. 2013;37:200-10.

\section{Figures}



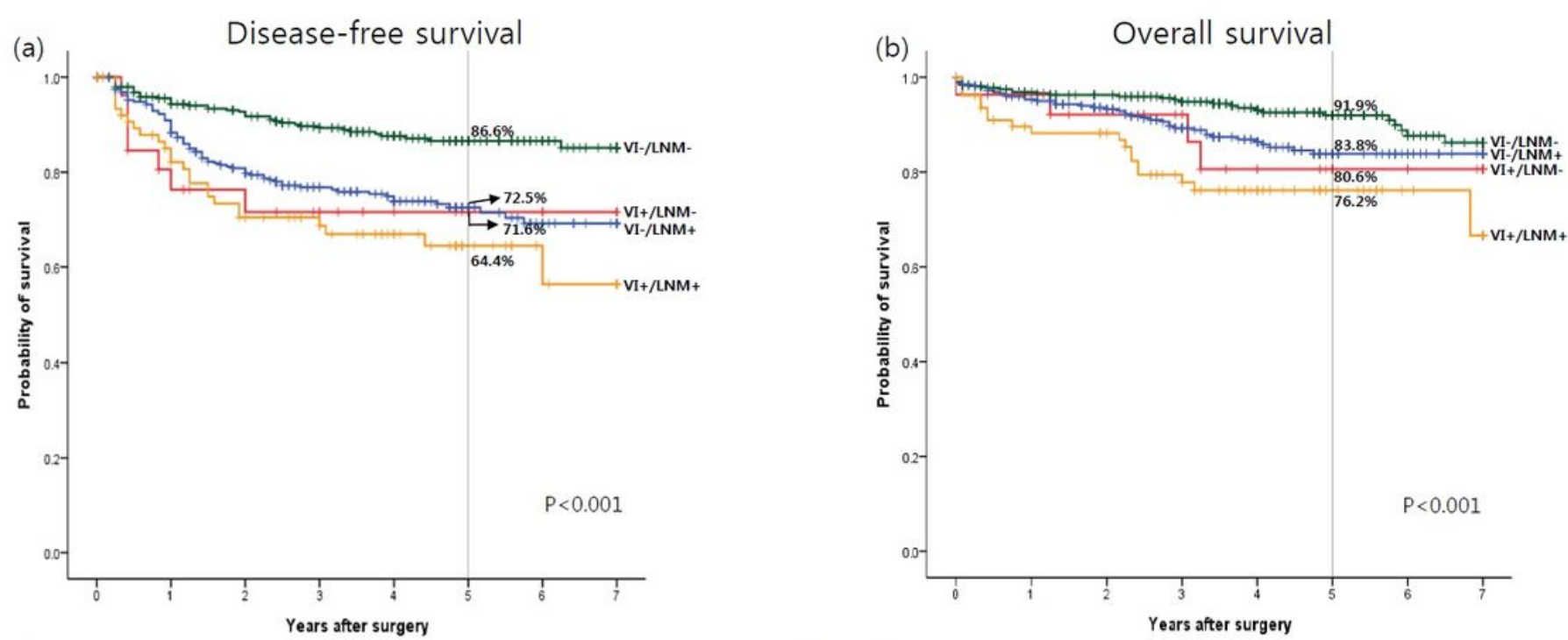

No. at risk

Group I

$\begin{array}{lllllll}357 & 308 & 284 & 236 & 191 & 112 & 73 \\ 27 & 19 & 16 & 13 & 10 & 7 & 5 \\ 327 & 277 & 230 & 176 & 143 & 73 & 50 \\ 82 & 59 & 47 & 41 & 31 & 17 & 8\end{array}$

No. at risk

$-$\begin{tabular}{cccccccc}
$\begin{array}{c}\text { Group I } \\
\text { (VI-/LNM-) }\end{array}$ & 357 & 319 & 301 & 251 & 202 & 120 & 78 \\
\hline $\begin{array}{c}\text { Group II } \\
(\text { VI+/LNM-) }\end{array}$ & 27 & 24 & 20 & 17 & 12 & 9 & 7 \\
\hline $\begin{array}{c}\text { Group III } \\
(\text { VI-/LNM+) }\end{array}$ & 327 & 296 & 263 & 201 & 162 & 82 & 59 \\
\hline $\begin{array}{c}\text { Group IV } \\
(\text { VI+/LNM }+)\end{array}$ & 82 & 65 & 62 & 49 & 35 & 20 & 9
\end{tabular}

\section{Figure 1}

Kaplan-Meier survival analysis according to the groups in stage I-III colon cancer. (a) Disease-free survival. (b) Overall survival. 
(a) Disease-free survival

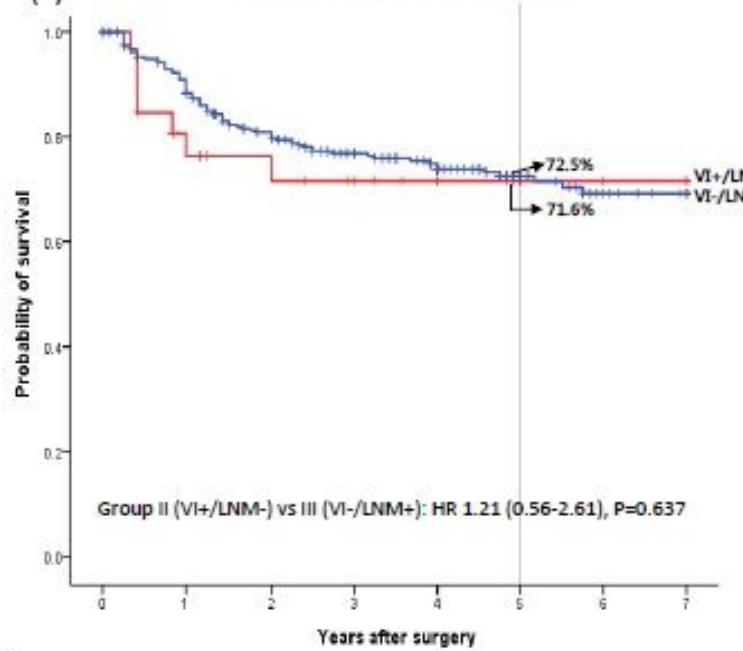

No. at risk

\begin{tabular}{cccccccc}
$\begin{array}{c}\text { Group II } \\
(\text { M }+ \text { LNM-) }\end{array}$ & 27 & 19 & 16 & 13 & 10 & 7 & 5 \\
\hline $\begin{array}{c}\text { Group III } \\
\text { (M-LNM+) }\end{array}$ & 327 & 277 & 230 & 176 & 143 & 73 & 50
\end{tabular}

(c) Disease-free survival

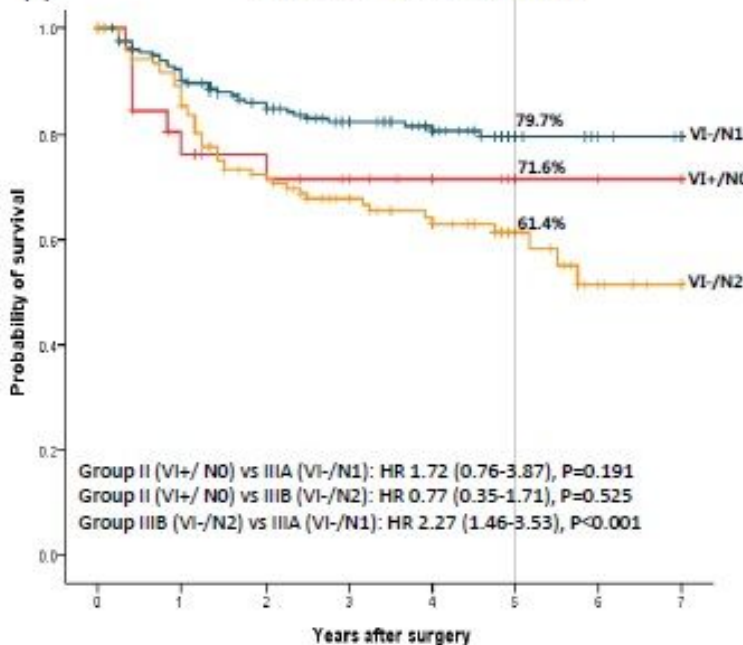

No. at risk

Group II

(VI+INO)

Group IIIA

(VI-IN1)

Group IIIB

(VI-N2)

\begin{tabular}{|ccccccc}
27 & 19 & 16 & 13 & 10 & 7 & 5 \\
203 & 173 & 150 & 116 & 93 & 51 & 38 \\
124 & 104 & 80 & 60 & 50 & 22 & 12
\end{tabular}

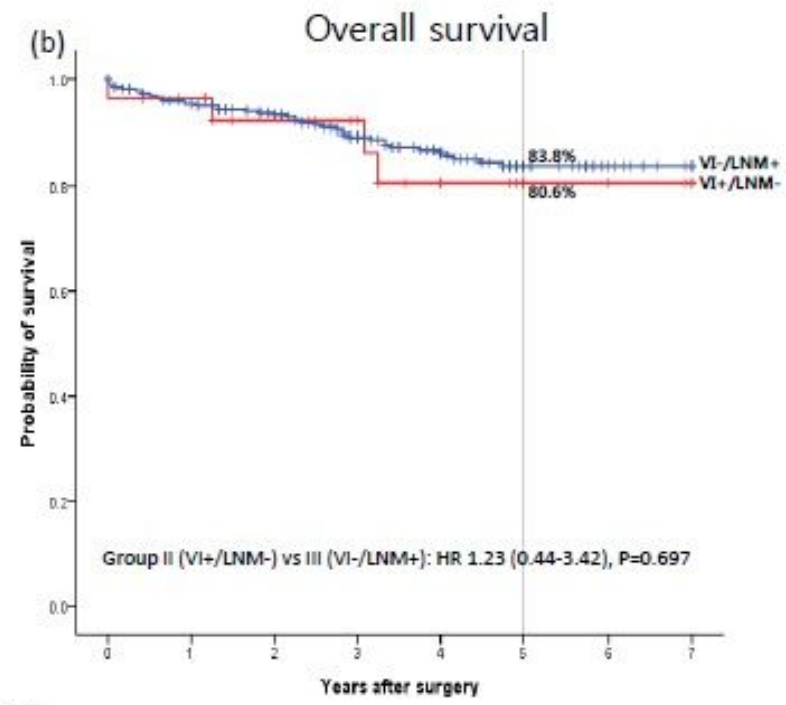

No. at risk

\begin{tabular}{cccccccc}
$\begin{array}{c}\text { Group II } \\
\text { (VI+/LNM-) }\end{array}$ & 27 & 24 & 20 & 17 & 12 & 9 & 7 \\
\hline $\begin{array}{c}\text { Group III } \\
\text { (VI-LNM }+ \text { ) }\end{array}$ & 327 & 296 & 263 & 201 & 162 & 82 & 59
\end{tabular}

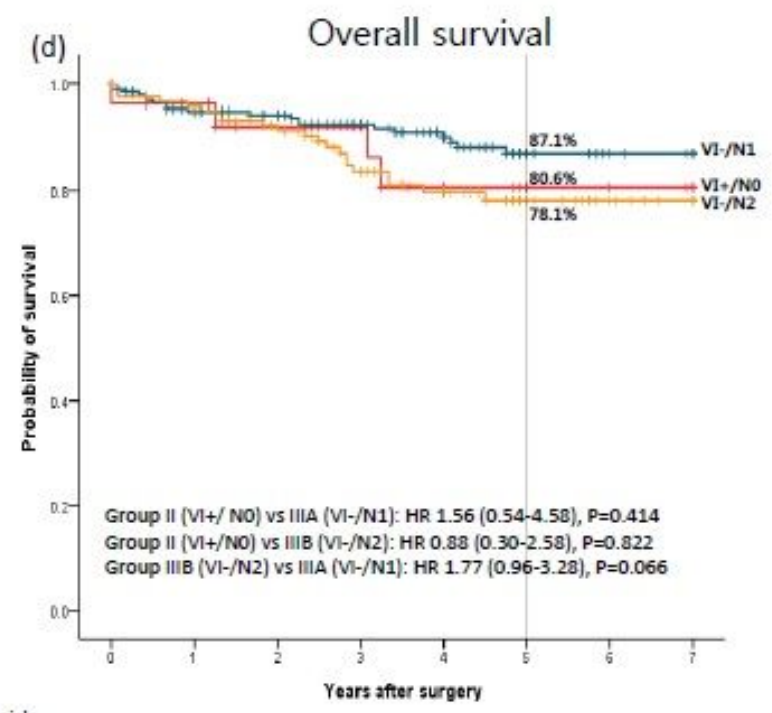

\begin{tabular}{cccccccc} 
No. at risk \\
$\begin{array}{c}\text { Group II } \\
\text { (VI+N0) }\end{array}$ & 27 & 24 & 20 & 17 & 12 & 9 & 7 \\
\hline $\begin{array}{c}\text { Group IIIA } \\
\text { (VI-IN1) }\end{array}$ & 203 & 182 & 165 & 130 & 103 & 55 & 41 \\
$\begin{array}{c}\text { Group IIIB } \\
\text { (Vl-IN2) }\end{array}$ & 124 & 114 & 98 & 71 & 59 & 27 & 18
\end{tabular}

\section{Figure 2}

Kaplan-Meier survival curve in subgroup analysis according to the status of vascular invasion (VI) and lymph node metastasis (LNM). (a) Disease-free survival (DFS) between VI+/LNM- and VI-/LNM+ patients. (b) Overall survival (OS) between VI+/LNM- and VI-/LNM+ patients. (c) DFS between VI+/LNM-, VI-/N1, and $\mathrm{VI}-/ \mathrm{N} 2$ patients. (d) OS between $\mathrm{VI}+/ \mathrm{LNM}-$, $\mathrm{VI}-/ \mathrm{N} 1$, and $\mathrm{VI}-/ \mathrm{N} 2$ patients. 